\title{
The relationship between rivers and cities: influences of urbanization on the riverine zones - a case study of Red River zones in Hanoi, Vietnam
}

\author{
L. H. Phong \\ Department of Genie Civil and Urbanism, \\ National Institute of Applied Sciences of Lyon, France
}

\begin{abstract}
In many megacities throughout the entire world, the relationship between cities and rivers is always considered fundamental to urban history research because of their profound interactions. Particularly, in the Southeast Asian countries, where wet rice cultivation is the base of culture, the river that brings the alluvium is indispensable to the development of a city. In this paper we will examine the extraordinary case of Hanoi, the capital of Vietnam, and the Red River. This river has massive influences on the urban development of ten cities in the north of Vietnam and is considered a source of life for the inhabitants who live along its two banks. In the case of Hanoi, the Red River was connected to the inner river system that made Hanoi a complete form of a river city. This structure, combined with over 1000 years of Hanoi's urban history, created the different interesting settlement morphologies along the Red River from the centre to the periphery which all related closely to "water". Nevertheless, in the last 20 years, Hanoi's strong urbanization and the instability of the Red River's complicated hydrology make the very remarkable transformations in urban morphology, landscape and environment of this city in general and the riverine zones in particular. For example, in respect to the environment, illegal construction and excessive sand exploitation causes serious erosion and threatens the quality of the soil. As a result, the high levels of water chemical components are evacuated into the river. These components pollute the water and directly harm the inhabitants' health. So, to understand more thoroughly these changes, an interdisciplinary research method that covers many different fields such as urban
\end{abstract}


planning, architecture, geography, and the environment has been carried out. This paper will extract part of the research in analyzing the transformations in some aspects of riverine zones and conclude by proposing some directions for a sustainable perspective of the relationship between Hanoi, the Red River and the riverine zones.

Keywords: cities, rivers, dike, urbanization, inundation, environment, infrastructure, transformations, sustainable, agriculture, villages, heritage.

\section{Introduction}

From the very early beginning of human life, water has played an essential role in the naissance and the development of societies. All the biggest civilizations such as the Ancient Egyptians or Indians have settled along the biggest rivers (Nile and Ganges). The rivers provide not only a water source and rich alluvium for the cultivation and transport, but they also contribute to form the very specific characteristics of these cities. These characteristics are based on the natural particulars of the region where the water stream flows across and on the ways people utilize and treat the water [1].

In Southeast Asia, where wet rice civilization was born, water from the rivers is the most important thing that forms the base of culture of this region. Most of the rivers in this region have origins from the mountains in the north of Asia (Tibet and Himalayan mountains) and flow mainly from north to south or from northwest to southeast. The rivers distribute a huge amount of alluvium and sediment that raise the rice fields and planted trees along their banks. Hence, the archeological relics showed that the first groups of inhabitants began to settle officially along the river banks about 4000 years ago. This kind of settlement formed the base of the Southeast Asia specific agricultural culture and historic interactive relationship between rivers and cities. In general, this relationship is affected by many aspects and also causes lots of risks. One of these risks is inundation and flood from the rivers because of an unstable hydrologic regime and a complicated monsoon climate. This type of climate causes an immense precipitation in rainy season (normally from July to September). That makes discharge water of these rivers alter greatly between rainy and wet season. As a result, the inhabitants started to build the dike early in order to better control the rivers' hydrology regime. The dike is considered not only as a barrier protecting the city from flooding, but also as a control measure that manages water irrigated to the rice fields. In addition, the dike stretching along the city can create an extraordinary and varied urban landscape. So, the dike has become an important element that affects the interactive relationship between rivers and cities.

In order to better understand this relationship, this paper will examine the case of the Red River in the north of Vietnam and the capital, Hanoi. In analyzing the contemporary situation of this river, we will have a panoramic view of its importance to this city, by the way it connected to the city and how this city treated its complicated hydrology regime. However, in recent years, the roles of the Red River to the capital's urban development tendencies have changed a lot. So, to re-evaluate this position, we will study the transformations 
of the river zones under the heavy pressure of urbanization, especially in the urban morphology, infrastructure and landscape. These transformations are results of a transition between many different processes. The urbanization and peri-urbanization are the most important processes that make the very remarkable changes in politics, economy and transport, in particular from the period of Revolution in 1986 (Doi Moi), the moment when the Vietnam Socialist Party decided to change the economic direction from the system of budget subsidies to open market economy. Secondly, the capital's urban development strategies and climate changes also have major influences on these river zones.

\section{The crucial roles of the Red River and its riverine zones for Hanoi and the appearance of the dike}

\subsection{Roles of Red River and the appearance of the dike}

Before examining how the river zones are transforming, we have to study the importance of the Red River to the cities in the north of Vietnam, especially Hanoi, the capital.

Historically, after a long Chinese colonial period (1000 years), the Vietnamese people gained the liberty in 938 in the dynasty of Ngo. Not long after, in October 1010, King Ly Thai To decided to set Hanoi as the new capital of Vietnam because of its advantages in the topography and strategic position [1]. The Red River was used in such a unique way for this historic change. From there, in the context of Hanoi's urban development, the Red River has always been one of the most important elements.

Firstly, this river is the very first source supplying water and alluvium that nourishes the paddy fields in the north of Vietnam. Each year, about a million tons of alluvium and sediment is brought by the Red River to consolidate the sols and its basins, while by constructing the dike, its water is used efficiently for the drainage and irrigation of the agriculture. This can also explain the origin of the word "Red" in its name: the color of the sediment and alluvium. In addition, an immense debit of the river is also a crucial element that assures a stable productivity of the rice and the other fruit trees.

Secondly, throughout history, this river was a crucial natural barrier protecting Hanoi from the enemies from the north, in particular the Chinese. There were 3 times when the Red River and its branches became the battle field where the enemies were beaten. Secondly, the Red River is the life-line of the fluvial transport that can connect most cities and provinces in the north of Vietnam by its branches.

Finally, combined with the complicated system of inner lakes and rivers of Hanoi, the Red River played two important roles in transport and water evacuation system of Hanoi: before flowing across the city, it divided in some branches that flowed interiorly in the city, and they met each other in the south of Hanoi and went to the sea. These branches reduced considerably the force of Red River's water in the rainy season and were indispensable to the inner fluvial transport system of Hanoi. One of the most important branches of the Red River 
was To Lich River. From the 11th to the 19th century, this river used to flow from north to south, across the ancient citadel of Hanoi and connected the most essential parts of the capital. However, this river is now representative of the transformations of the inner river system of Hanoi (its changes will be analyzed in the following parts).

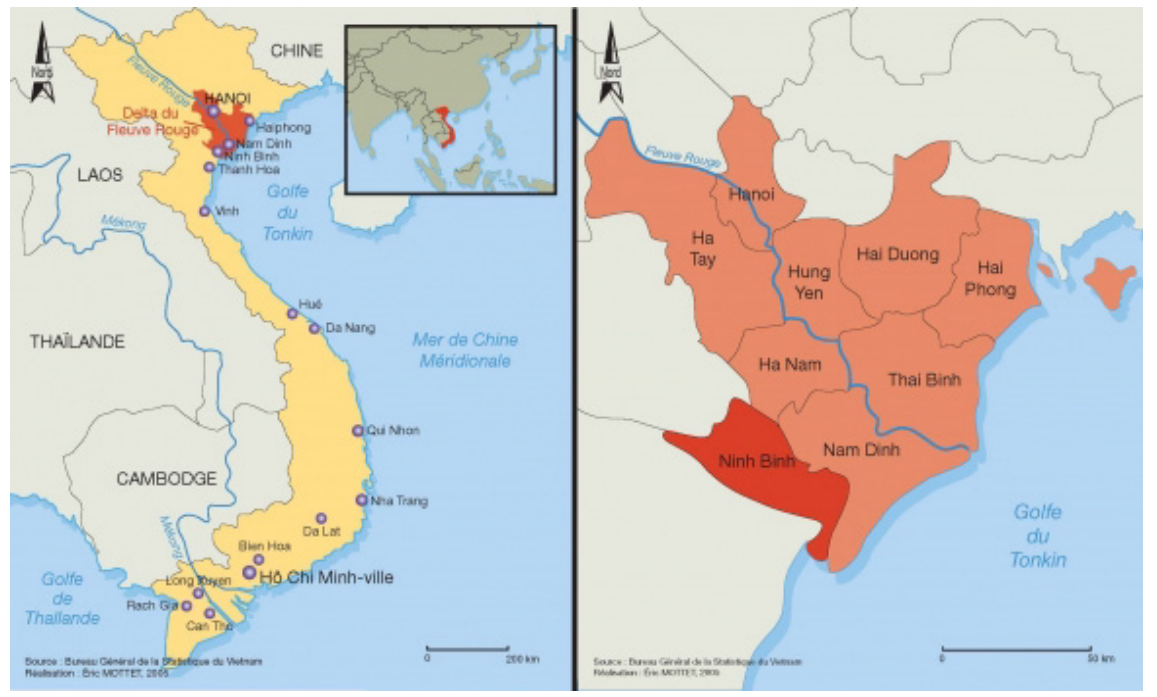

Figure 1: Position of the Red River in the north delta of Vietnam. Source: http://vertigo.revues.org/7782.

These reasons can explain a very early settlement along two banks of the Red River, in particular the right bank (or the south bank). At first, river banks were covered by the artisanal villages whose inhabitants followed King Ly Thai To in order to settle in the new capital. Step by step, there were the agricultural villages whose inhabitants were from the other provinces coming to Hanoi to break fresh ground.

On the opposite side, the Red River has also negatively influenced the capital because of its unpredictable annual flood regime. In the past, before there were any hydro-electricity projects, Red River's flood always threatened Hanoi. As analyzed, because of the monsoon climate regime, the difference in the water levels in the rainy and dry seasons is immense: while in the dry season, water debit can reach only $1000 \mathrm{~m}^{3} / \mathrm{s}$, in the rainy season (from July to September), this number can reach over $10,000 \mathrm{~m}^{3} / \mathrm{s}$ and water level augmented sometimes to $14 \mathrm{~m}$ (we can mention some historic floods which caused serious damages to Hanoi: in 1945, the Red River water augmented to $14.05 \mathrm{~m}$ and the area flooded was about $310,000 \mathrm{ha}$; in 1971, the water level reached $14.13 \mathrm{~m}$ and about 100,000 people in the north of Vietnam were killed in this historic catastrophe) [2]. 


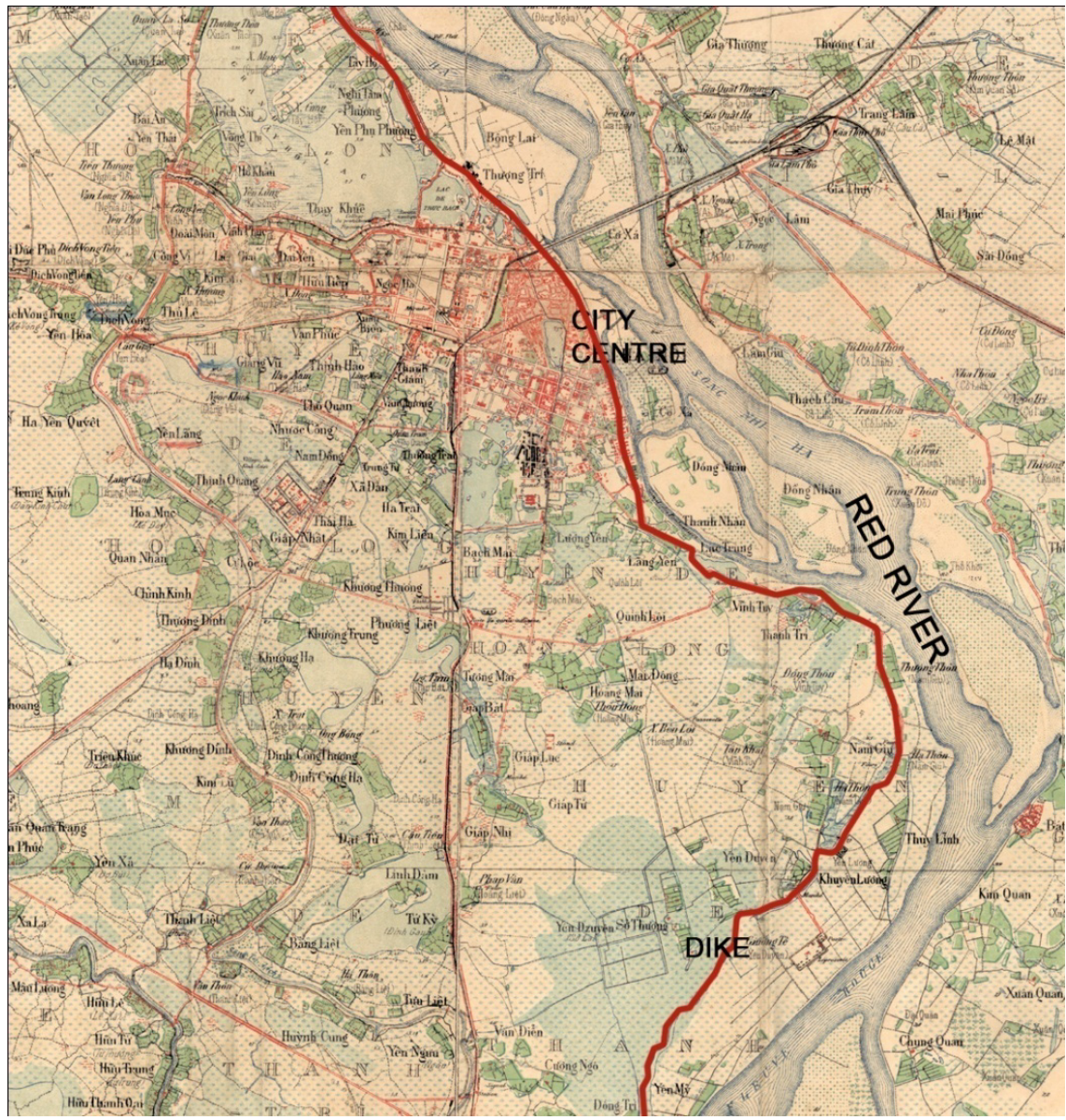

Figure 2: Master plan of Hanoi in 1912. Scale 1:50000. Source: Ecole Nationale Supérieure d'Architecture (ENSA) de Paris-Belleville.
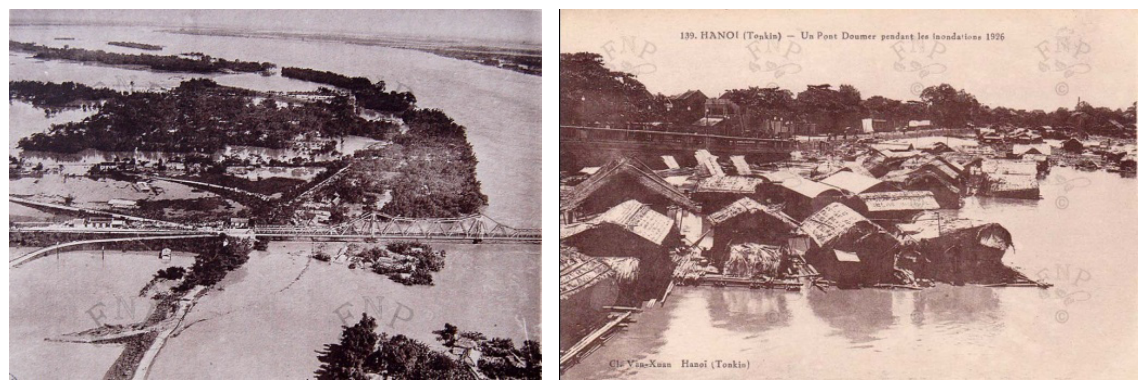

Figure 3: The historic flood in 1926. Source: http://hanoilavie.com/. 
This worrying menace required creation of an infrastructural project which can prevent floods in the rainy season but can also help to get water from the river in the dry season for agricultural irrigation. As a result, the dike has been built and has been consolidated at the same time with the commencement of the capital over 800 years ago. By constructing the dike, the Vietnamese have an efficient method to control the water and flood knowing that the height of the dike now reaches about $14.5 \mathrm{~m}$ (equal to the highest water level in a cycle of 100 years) $[3,4]$.

Nevertheless, the dike has also become an obstacle that separates the city and the river. Since the dike became higher, the flood became crueler because the huge amount of alluvium that rests in the middle of river can't continue to consolidate the banks. This quantity of alluvium makes the water level higher progressively. That's the reason why the flood risk has become more dangerous since the dike has become higher.

In addition, the social problems are remarkable. The dike has divided the city into 2 different parts: the part located inside the dike which is well protected and better equipped in infrastructure and social service; and the part located outside the dike is always threatened by the river's flood and is almost forgotten. This outside-dike part progressively becomes the assembly point of the immigrants and poor people who can't afford a comfortable resident inside the dike.

Technique is also a big problem. The dike requires frequent maintenance. This seems to be very expensive because of its gigantic length (the interior part of the dike of Hanoi is about $80 \mathrm{~km}$ on both sides of the river) and demands a lot of effort because only a small crack can permit water to go through the dike and threaten the city. For example, the history of water management in Hanoi has indicated that "the termites" are one of the most dangerous and serious problems of the dike maintenance!

\subsection{Riverine zones: important parts of Hanoi}

The roles of the Red River can also be reflected in riverine zones. These zones have the primary role as a green corridor that assures a soft transition from the city to the river thanks to the early installment of agricultural villages. These villages, with their traditional morphologies and their landscape which are very close to nature are important elements that harmonize the urbanized parts and nature.

Secondly, since the naissance of Hanoi, the fluvial transport was the most important way that connects Hanoi and the other cities and provinces in the north of Vietnam. Moreover, for military reasons (to avoid the attack of the enemies from the north), through its long history, the capital has limited the enlargement of the sphere to the left bank of the Red River. Consequently, most of the important fluvial and military infrastructural projects such as ports or barracks are installed on the right bank of the river and stretch from the centre to the periphery. In respect of culture, with their traditional and specific characteristics, these agricultural villages have a grand potential to become cultural heritage that deserves to be preserved and to be exploited as attractive tourism sites. In addition, in the period of the Revolution, especially from 2008, when a grand 
project to form a new capital was carried out, that merged Hanoi, the neighboring province of Ha Tay and some parts of Hoa Binh and Vinh Phuc, the riverine zones in the south of Hanoi became a very important transport transition point that crossed new roads and highways connecting the city centre and the new parts of capital and the other important cities in the northeast of Hanoi. Finally, the river zones in the south have an extremely important role to the water management of Hanoi. Specifically, Yen So quarter (a new quarter located in the south of Hanoi along the Red River) is concentrated by 3 evacuated rivers of Hanoi: To Lich River, Set River and Lu River. These 3 rivers lead pluvial water and used water from the residences of more than 3 million inhabitants who live in the centre to the Yen So water treatment plant. This plant will generally treat this used water before it is discharged into the Red River. In spite of their importance, these zones and the Red River now have to suffer a great pressure from urbanization and new urban development tendencies.

\section{The pressure of urbanization to riverine zones and its consequences}

\subsection{Social transformations: the case of outside-dike zones}

In recent years, under the pressure of urbanization, the demand for modernity and urban development tendencies, the roles of the Red River and the riverine zones have changed a lot.

Firstly, because of the water control activities in the upstream zones and the climate changes, the Red River's hydrologic regime becomes more unpredictable and more unstable and there is also a rare risk of flooding coming from the Red River. Worrying about flooding has never been eliminated but has still persisted: if there's an incident that happens to the hydro-electric dams upriver, there'll be a very brutal catastrophe to the downriver cities, especially Hanoi, because an immense amount of water will be discharged immediately, the debit of the Red River will increase suddenly, and in that case, even the highest dike level can't prevent the water from flooding the city. So, in order to reduce the force of flood, softening the riverbank and prohibition of construction in the outside-dike zones are indispensable. However, under the influence of urban sprawl and the new housing demands, the part of the Red River outside the dike is being invaded and consolidated seriously. This invasion can be explained by the complicated community structure in these residential quarters along the Red River: the origin of the inhabitants settled in these zones isn't homogenous from the centre to the periphery: while in the periphery, the inhabitants in the ancient agricultural villages who don't have much money to buy a house inside the dike have to move to the outside zone where land price is cheaper because of its insecurity, in the central quarters, a lot of people from the other provinces have moved to Hanoi to find a temporary job such as manual labor or vendors in the city centre [5]. 


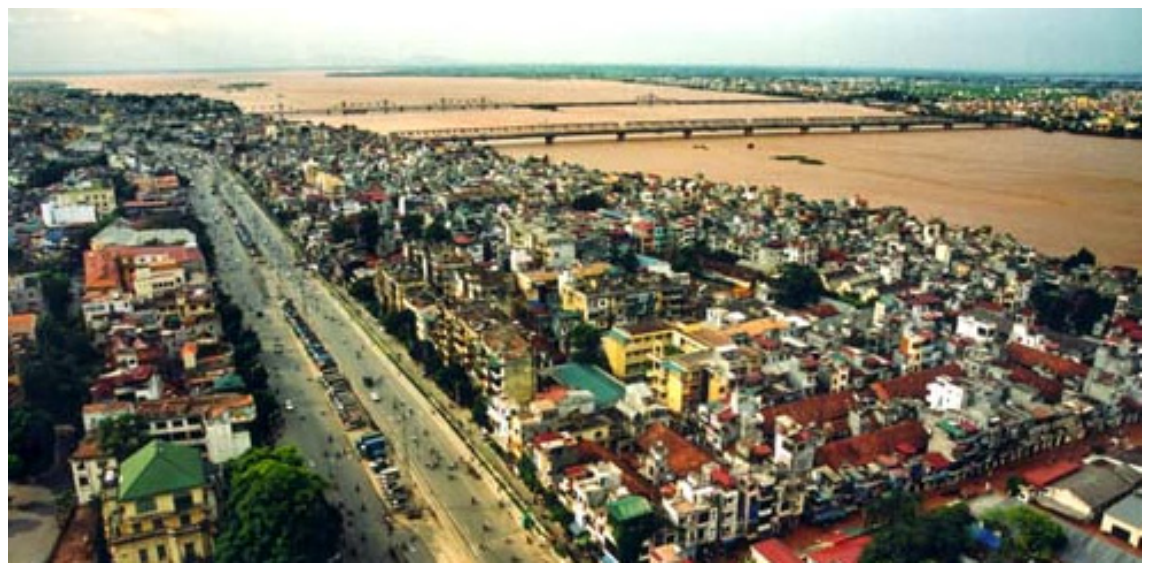

Figure 4: The outside-dike zones in city centre are totally invaded by construction. Source: http://ashui.com/.

With a low and unstable income, they can't afford to buy or even hire a residence. They then choose these zones outside the dike near the centre to live spontaneously, because from there it's very easy to access the city centre and they don't need to pay much for this provisional dwellings. So, all of these inhabitants have to consolidate the sols so that they can build a new house. This will cause some considerable consequences to the city: knowing that the infrastructural system in these zones is backward, even in the central area, these zones find themselves with many technical and environmental problems: there isn't any used water evacuation system or potable water distribution system. The immigrants have to use water from the Red River for their daily life. In addition, their used water and garbage is usually discharged directly into the river. This will increase the risk of disease and pollution. In the construction side, they build the floating houses from cheap materials in the river that seem to be very unstable and dangerous for their own life. For all of these reasons, the outsidedike inhabitants group are the major social problem of Hanoi. In "Hanoi Master Plan to 2030 and Vision to 2050", the leaders of Hanoi manifested an ambition of releasing these unsettled zones and renovating the outside-dike zones into a large green corridor of the capital. However, a reality that prevents the government from treating these social problems is the fact that there are no rules for controlling the construction on the rivers, so the authorities are very confused on how to treat this phenomenon. Moreover, on the social side, the lack of occupation and administrative control by authorities for a long period of time, also permitted them to settle in these zones and now it's very hard to encourage the inhabitants to leave. As a result, they survive as the minor isolated communities which can also increase the risk of social evils: they can't afford their daily life, the children don't have occasion to go to school, and their public spaces are limited to being around the river [6]. The most difficult things to overcome are the modest spaces and relationship of this community with others. 

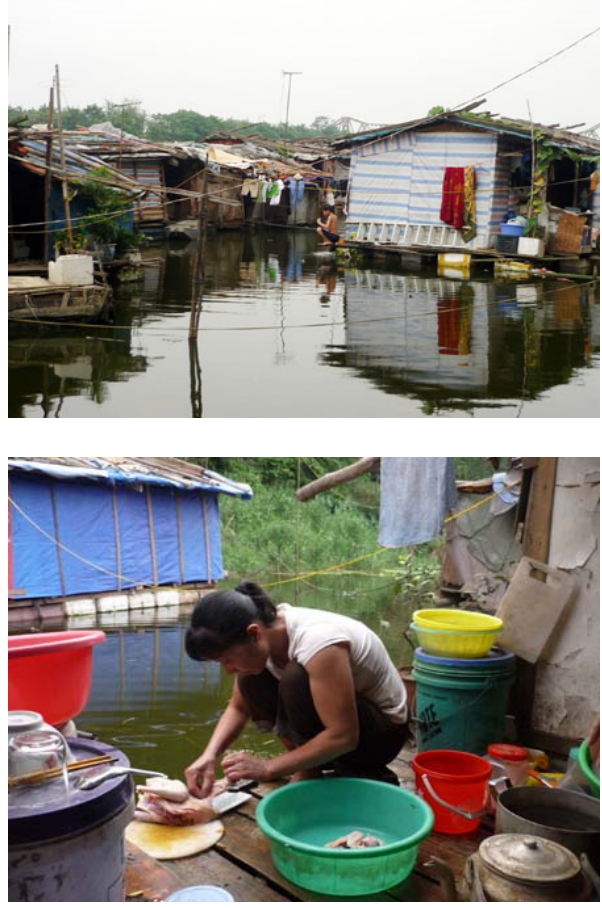

Figure 5: The inhabitants who live in the outside-dike zones with an unstable life. Source: http://baotintuc.vn.

From a geological aspect, knowing that each year the Red River brings a huge amount of alluvium to its two banks, the construction and the consolidation of the soft terrain outside the dike will restrain the consolidation of alluvium to the two river banks. And, as analyzed, if there's an incident with the dams in the upstream zones, the water level will augment gradually and threaten the city. So, the construction in the floodplain zones can be one of the main reasons that increases the risk of inundation (knowing that the level of the Red River in this part of Hanoi has increased by about $1 \mathrm{~m}$ in the last 60 years, and the base level of land inside the dike is now much lower than the level of river water). That's why the floodplain zones outside the dike are sensible but also very meaningful to Hanoi: they are the transitional zones between the inner city and the river, that are considered as a "soft corridor" (about $30 \mathrm{~m}$ from the edge of the water), which can make sure that the terrain is not too consolidated and assures the ease of evacuation of the water. In these zones, the construction must be limited or even prohibited. However, the biggest problem is the late promulgation of this rule which was adopted a long time after the settlements of inhabitants in these zones caused many difficulties in the clearance and resettlement for the existing households in these zones. A survey of JICA in 2007 showed that there were 12 quarters that were located totally outside the dike and there are some quarters 
which have more than 5000 households that are located in these floodplain zones - this number had not stopped growing [3].

Secondly, the transformations in the riverine zones are the result of the transition of different processes (such as urbanization; peri-urbanization; urban development strategies) whose impacts reside in the morphological, infrastructural and social transformations in agricultural and artisanal villages located along the river. The most remarkable change in these zones is the disappearance of these traditional villages. In the past, the Red River was considered as the most important source of irrigation water; moreover, the land along the river was the most effective for the agricultural activities to these traditional villages. Therefore, these villages have a very long history in wet rice culture which can explain their very specific characteristics in spatial organization. In general, because of a self-economic system, a traditional village is quite closed in both social structure and spatial form: a village is located on the high and flat ground, that isn't too far from the paddy fields and the river (this location is ideal for agricultural activities). Bamboos are planted around the village just like a natural defense barrier. The villagers rarely go out of their villages. They live in villages for their whole life; they get married to people in the same village or in the neighboring villages. From an architectural side, most of the houses in a traditional village are constructed using the local materials: the bamboos and the wood trees planted in the garden are used for the structure of houses; food is provided by the domestic animals and fishes in the ponds. Faeces from animals are used to fertilize trees. Most of the elements in a traditional house make a complete ecological cycle. That's why the villagers don't need to move out of their homeland. In Vietnam, the countryside traditional morphology is always considered as the base of traditional culture and also urban form, so all of their changes need to be examined with extreme caution before being carried out [7]. Nevertheless, with the onslaught of urban sprawl, some of these villages became the urban districts or villages located in the cities' periphery where new roads and new highways intersect. As a result, the urban tendencies modify the tradition, including architectural morphology, spatial morphology and social structure. In addition, the village located along the river suffers even more pressure.

\subsection{Transformations in the infrastructure system: the case of Yen So quarter}

The most remarkable transformations of these riverine zones focus on the water evacuation system. This part will analyze a very typical case of the Yen So quarter in Hoang Mai district. This quarter used to be known as Yen So village in Thanh Tri suburban district, in the north frontier of Hanoi, but since the project of Hanoi's urban enlargement strategies of 2003, this village became a new urban quarter of Hanoi's new urban district Hoang Mai. This quarter is extremely important for the water evacuation of Hanoi. Located in the north of Hanoi, on the right bank of the Red River, having the lowest terrain level in comparison with the other areas of Hanoi, being the end of 2 important evacuation inner rivers of Hanoi (Kim Nguu and Lu), Yen So is considered as a 
used water concentration point of Hanoi receiving about $275,000 \mathrm{~m}^{3}$ used water each day ( $50 \%$ of total used water volume of Hanoi) [8].

So, besides the socio-economic transformations of an agricultural village, urbanization and urban sprawl has meant a lot of changes and new problems in this quarter. In the past, thanks to the dense inner lakes and rivers system, Yen So didn't have to suffer a strong pressure from water evacuation. However, since urban sprawl has become stronger and faster, the inner rivers and lakes system are progressively filled and replaced by the housing land and the new residential projects, the major part of pluvial and used water concentrate in Yen So quarter. Knowing that the topography of Hanoi is quite flat, the pluvial water evacuation is difficult. This problem has persisted for a long time, and it seems to be more severe now that there are very few embouchures remaining to keep pluvial water temporarily. In order to resolve this problem, the Committee of Hanoi installed a high productivity water treatment plant in Yen So quarter in 2008. Although the productivity of this plant has doubled since 2010 after a historic flood in 2008 (this flood is considered as the most serious flood ever in Hanoi) [9], in the rainy season this plant may become overloaded because of an immense pluvial water discharge.

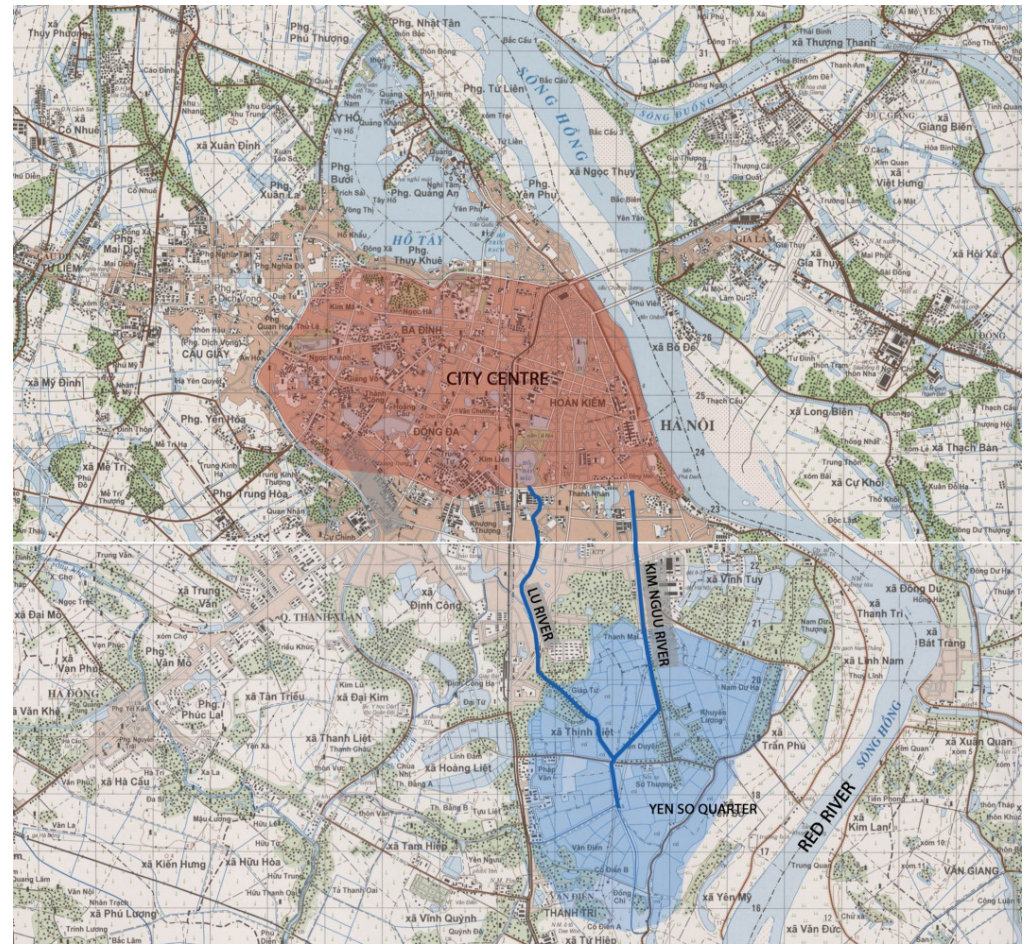

Figure 6: Master plan of Hanoi in 2000 illustrates the position of Yen So quarter, concentrated by three evacuated rivers of Hanoi. Scale: 1:50000. Source: ENSA Paris-Belleville. 
In addition, the overload of used water evacuation can also cause some worrying environmental problems to Yen So's inhabitants, primarily, used water from the rivers can be a source of pollution, then if the treatment isn't absolute, the toxic chemical substance remaining in the water can pollute in one hand the groundwater source and in the other hand the Red River water which can threaten the life of the inhabitants who live in the downriver zones next to the main sewer of water treatment plant $[10,11]$.

As a result of a two-sided interaction, these transformations of riverine zones have also impacted on the urban development situation in Hanoi in many aspects.

The transformations in morphology and infrastructure system of this quarter have massive influences on Hanoi's evacuation system. Yen So has been known by a system of 5 important lakes whose mission is keeping and treating used water. But being invaded by many new public and residential projects, the area of these lakes has reduced considerably in the recent years. This brings about risk of inundation and environment pollution to this quarter and more seriously, the trapping of water evacuation in Hanoi.

In the landscape, the $40 \mathrm{~km}$ length of zones located outside the dike along the river plays an extreme important role to Hanoi. It forms the remarkable edges between city and river, contributes to creating precious open space with many modes of social activities. This type of landscape assures an equilibrium, a soft transition from urban zone to nature. Furthermore, these spaces are attached to many different traditional urban logic settlements (agricultural villages, artisanal villages. etc.) and all of them offer a huge potential for tourism [7]. Having the typical traditional form and countryside landscape, the agricultural and artisanal villages will be the attractive destinations for the ecologic and agricultural tourism, Bat Trang pottery village is a typical example [12]. The negative transformations in the dike zones can firstly threaten this sustainable and important structure and cause serious damage to the equilibrium of landscape of Hanoi. Secondly, these transformations will have negative influences on the flood regime of the Red River. From a hydrology point of view, the Red River is now an old river, so all the activities on its two banks will affect its hydrologic regime. All these points are for the purpose of confirming that to ensure a sustainable development of the Red River zones, all projects related to this river have to be carried out carefully and with a profound knowledge not only in the hydrologic regime but also in cultural, historic and urban development processes. A very remarkable example which comes from the failure in the lack of research is the project "new city on the banks of the Red River": in 2007, this collaboration project between Vietnam and Korea whose ambition is to renovate the two banks of the Red River was carried out. To make this ambition real, the Korean experts proposed a solution that took full advantage of the "golden land" on two banks of the Red River where the residential and commercial zones with the towers and high buildings dominated over the public and green spaces. Although, with ambitious drawings and planning maps, this project manifested a lack of knowledge in both the hydrological system of the Red River, relationship between the river and Hanoi, and also the urban history of the capital. Such 
projects threatened the zones inside the dike by an excessive consolidation of the two banks and generally separate the inside-dike zones and the river. As a result, this project was criticized by Vietnamese geologists and architects and was not adopted by the Committee of Hanoi.

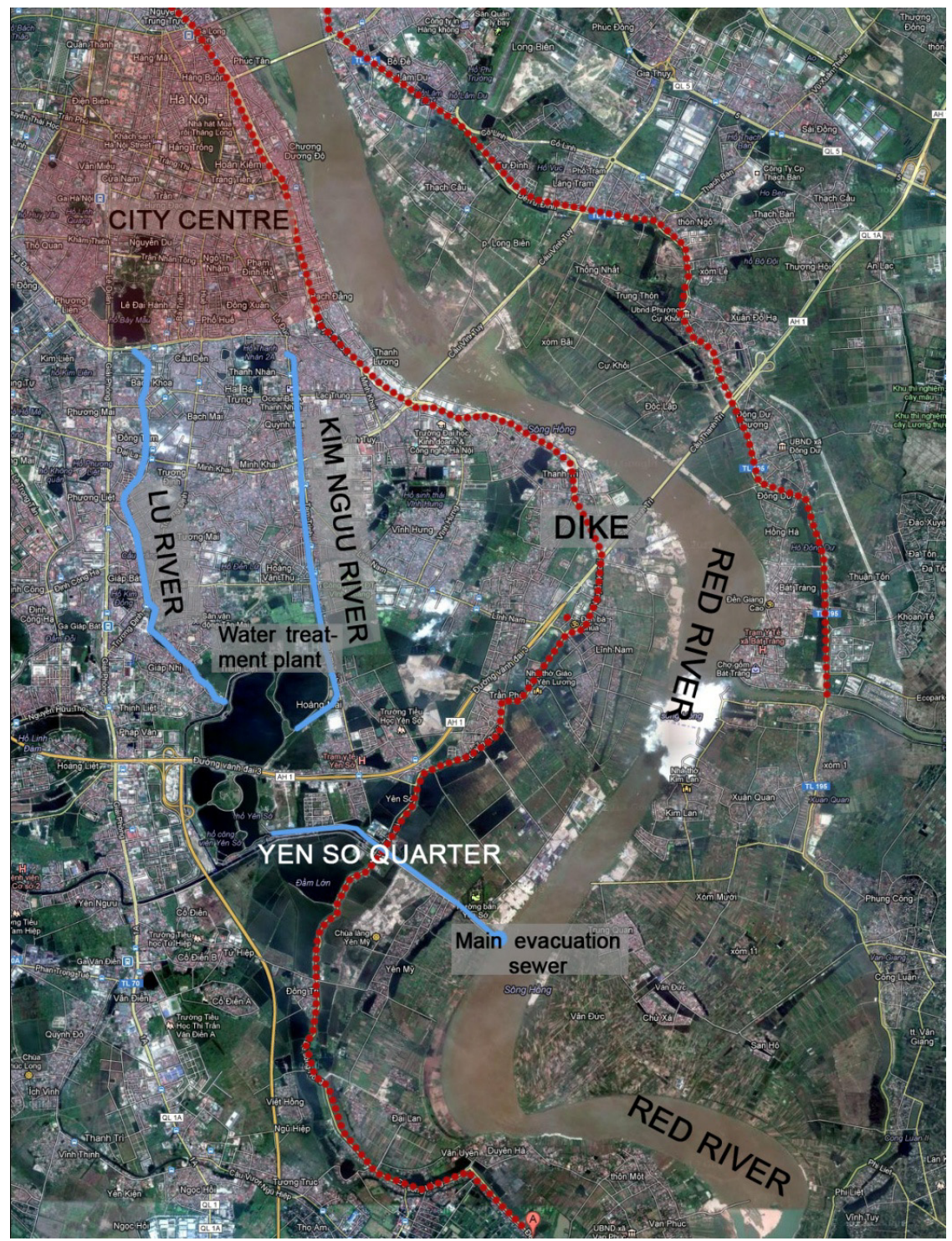

Figure 7: Satellite image of Hanoi (2012) showing that the area of water (lakes, rivers) of Hanoi in general and Yen So quarter in particular has reduced considerably in recent years. Source: https://maps.google.com. 


\section{Conclusion: relationship between Hanoi city centre, the Red River and riverine zones from the perspective of a sustainable development}

In general, the case of Hanoi and the Red River is very typical of the interactive relationship between cities and rivers in Southeast Asia where the rivers are primordial to urban development. In those cases, the river is on one hand a natural element, which connects cities and nature as well as harmonizing the environment of the city; and on the other hand a subsistence of inhabitants who live along the river. However, in the case of the Red River, the city and the river were not really connected. By protecting Hanoi from risk of catastrophes, the dike has been splitting this city and its river. To describe the declination of this relationship, Pierre Gourou, a famous French geographer, after many researches about Hanoi and the Red River delta, wrote in his wonderful book "Les paysans du delta Tonkinois" (The Farmers in Red River delta): "Red River was death in its adolescence" [13]; or in a recent article discussing the future of the Red River in the urban perspective of Hanoi, a senior Vietnamese architect approved: "from early 20th century, this city (Hanoi) has decided to turn its back on the Red River" [14]. These 2 phrases have proved that the Red River has no longer taken part or contributed to the urban development of Hanoi, and on the opposite side, this city didn't consider the Red River as an important natural component for a sustainable development. Nowadays, after many environmental and technical problems which are related to the infrastructure system, the demand of a sustainable development in Hanoi urban requires us to rethink about regenerating the relationship between this city and the Red River. In fact, a sustainable development can be understood like constructing a socio-economic house on an ecological environment foundation. This house can be accomplished only when we can link together all of these components. Specifically, in order to regenerate a sustainable relation between the Red River and Hanoi, there are 4 important problems covering many aspects that have to be resolved:

Firstly, the most important work is improving the dike system in order to reconnect the city and the river. In fact, the dike has been considered as a protection element, also as a barrier that separates the dialogue between innerdike part and the outside-dike part. As analyzed, this separation has caused many social and technical problems.

In the future, a new hierarchical dike system combined with the other infrastructure systems can be developed: the dike will be a hybrid infrastructure project: it can play multiple roles, on one hand as a protection infrastructure, and on the other hand as a connecting infrastructure and a public space (as long as the safety is always assured). In brief, this work of the dike's improvement contains 3 main missions: periodical maintenance; reducing transport pressure on the dike; diversifying social activities in the dike zones with assured safety.

Secondly, in parallel with renovating the dike system, making use of the riverine area is also essential work. As analyzed, the disappearance of traditional villages persists because of a pertinent question about cultural heritage 


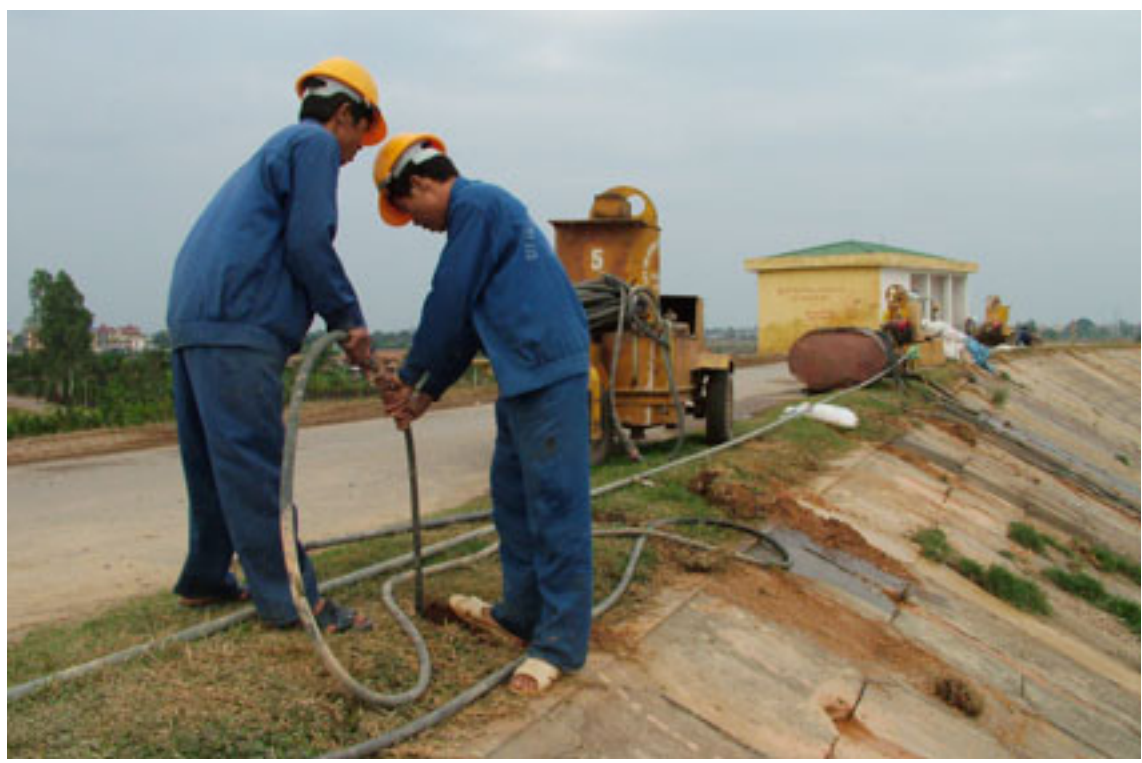

Figure 8: Workers are maintaining the dike by sucking out the water from inside. Source: www.baomoi.com.

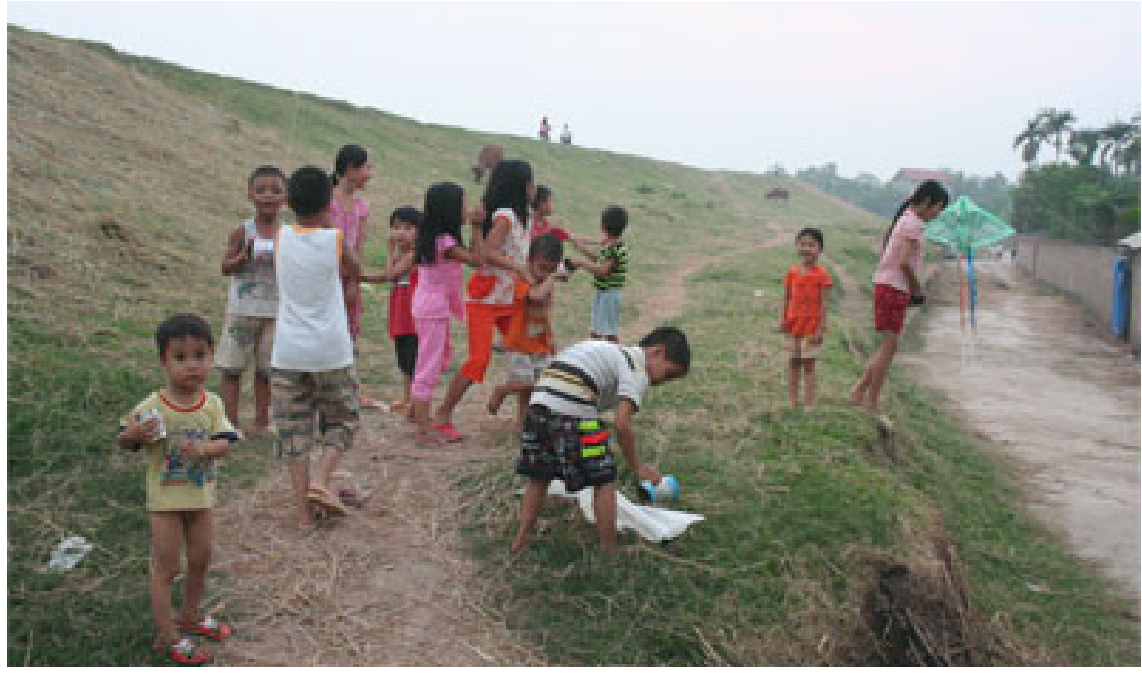

Figure 9: Children playing at the foot of the dike. Source: http://dantri.com.vn.

conservation; if the traditional villages remained, the climate change causes many difficulties to agricultural activities; low and unstable income from agriculture makes the farmers change their job [15]. As a result, the social 
transformations lead to physical transformations in these villages: traditional morphology is replaced by the modern urban forms, and in these river villages, the river bank area is the first to be affected. This bank area is forgotten and becomes the rubbish concentration points [16]. So, knowing that these villages are a potential cultural heritage, a reasonable tourism strategy will be an ideal perspective for both patrimonial conservation and making use of precious river bank space. In this perspective, an eco-agricultural tour or Vietnamese traditional architectural tour could be some interesting tourism ideas.

Thirdly, another important aspect is assuring a stable infrastructure system. As analyzed in the second part, the riverine zones are transitional between the city centre and the river, so it has to suffer a great pressure in many aspects, especially in the technical side such as water evacuation or transport. However, this system is still backward and not modernized. As a consequence, in the future, when the new urban and transport projects invade these zones, the overload of infrastructure system and environmental pollution are inevitable consequences. So, modernizing and renovating the infrastructure system in these zones has to be considered as the primary priority. Besides, in order to reduce pressure of the riverine zones, improving the general infrastructure system, in particular the drainage system of Hanoi has to be a priority.

Finally, in respect of the environment aspect, in order to achieve a sustainable development, we have to find a new strategy to link the nature and urbanized zones from the smallest units that form the city. For example, the ecological neighborhoods which use the wet-land model to filter preliminary used water before discharging into the public infrastructure system is an ideal model that can be developed. The advantages of wet-land focus not only on the treatment of used water, but also on the creation of a common park or garden for inhabitants, knowing that public space is now one of the most urgent demands of the new quarters. After that, the well located wet-land areas can help us to ensure a comfortable climate condition thanks to a huge water area. It will be a big airconditioning machine that equilibrates climate in summer and also a natural barrier that isolates the quarter from the polluted substance arriving from outside.

In brief, a sustainable development of Hanoi can be achieved only if we can reconnect the Red River as a natural part of urban body in resolving some aspects mentioned: the environment pollution, the infrastructure system and the use of river banks spaces. However, these problems can't be resolved separately, they have to be connected to the general urban perspective of Hanoi.

\section{References}

[1] Clément Pierre, Lancret Nathalie (dir.), Hanoi: The cycle of metamorphoses. Architectural and urban form. Research/IPRAUS, 2001.

[2] The historic floods in the history of Vietnam, dulieudiali.wordpress.com, $2 \mathrm{p}$.

[3] JICA, The comprehensive Urban development in Hanoi capital city of the Socialist Republic of Vietnam, (part 13 - special zones, final report, condition), 36p, 2007. 
[4] Nguyen Thanh Son, City, the dike and the river, Ashui.com, 7p, 2008.

[5] Hoang Van Chuc, Spontaneous immigration to Hanoi: Current situation and solutions, Edition de la Politique Nationale, 283p, 2004.

[6] Nam Hoang, Thu Trang, Ta Nguyen, Report from the plain in the middle of Red river, baotintuc.vn, 17p, 2012.

[7] Ha Phong Le, Influences of urbanization on the riverine zones in the north of Hanoi, Master dissertation, INSA de Lyon, (chapter 6 - transformations of an artisanal village on the bank of Red river - case of Bat Trang pottery village) pp. 114-140, 2013.

[8] $50 \%$ of used water volume of Hanoi will be treated in Yen So water treatment plant, www.thanhnien.com.vn, 2008.

[9] The productivity of Yen So used water treatment has been doubled, www.baomoi.com, 2010.

[10] JICA, The comprehensive urban development in Hanoi capital city of the Socialist Republic of Vietnam, Final report, (part 9 - water and urban hygiene), 55p, 2007.

[11] Tien Minh, peril of contaminated water of arsenic, petrotime, 2013.

[12] Dinh Quoc Phuong, The Architecture of Bat Trang, a Pottery Village in Hanoi, 41st ISoCaRP Congress 2005, 13p, 2005.

[13] Pierre Gourou, The farmers in the Tonkin delta, Editions Art and History, Paris, pp. 71-108, 1936.

[14] Ta Hoa Phuong, Red river city project: responsibility to the history, Ashui.com, 10p.

[15] Committee of Yen My village, Thanh Tri suburban district, Hanoi, New rural area development project, pp. 7-14, 2013.'

[16] Chu Thanh Thai, Traditional villages and the pollution treatment, Environment magazine, 12p, 2009. 